\title{
CASE OF POST EPILEPTIC HYSTERIA. EFFECT OF INHALATION OF COMPRESSED AIR. PHENOMENON OF TRANSFER.
}

BY DR. MARY PUTNAM JACOBI, M. D.

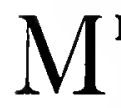

ISS R. K., æt. 35, suffering from epilepsy for about twenty years. Violent attacks infrequent, and patient often enjoys several months of quite good health: at other times, liable to frequent epileptical seizures, mingled with hysteriform attacks. Both are usually controllable by nitrite of amyl. Patient takes habitually 60 grains of bromide a day: often has taken three and four drachms, and with no marked benefit.

In October, Miss $\mathrm{K}$. suffered for a fortnight from a severc attack of gastric catarrh. Towards the close of this attack, which had been treated carefully, and without suspending the bromides, the patient had an epileptic fit of extreme violence, such as she was said not to have experienced in five or six years. After this fit, she suffered from marked nervous exhaustion, claimed to feel extremly "queer "in the head, to tremble all the time, to have sensation of numbness throughout the body, slight on the right, but very pronounced on the left side. There was no objective anaesthesia. The symptoms all pointed to a persistent effect in the cortical centres of the shock sustained during the epileptic fit. It was a question, whether, on account of this, the cortex had not yet regained its normal control over the subcortical vaso motor centres, and hence that some degree of spasm persisted in the cortical blood vessels, maintaining the anemia, or dyspncea of the cortical nerve tissue. I decided to try the effect of the inhalation of compressed air from the Waldenburg apparatus, and anticipated from this a double effect: Ist. The introduction of some more oxygen into the 
blood, which might serve to feed the dyspnœic cortical centres of the brain. 2d. An increased force of the heart, indirectly determined by the greater amount of blood in the systemic circulation, when blood should have been expelled from the lungs by the increased pressure of air within the air cells.

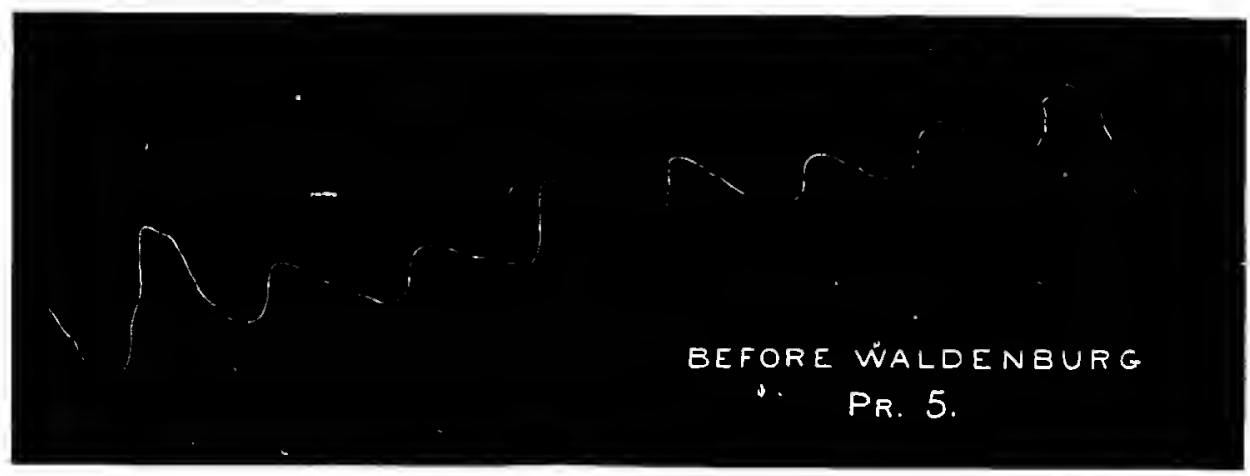

The accompanying pulse traces show the condition of the radical pulse before and after the inhalation. The trace No. I, taken before inhalation, is remarkable for its vertical and high percussion stroke, relatively rapid collapse, absence of dicrotism, very small tidal wave. These characters indicate a low arterial tension, against which the heart works with energy, but without much benefit.

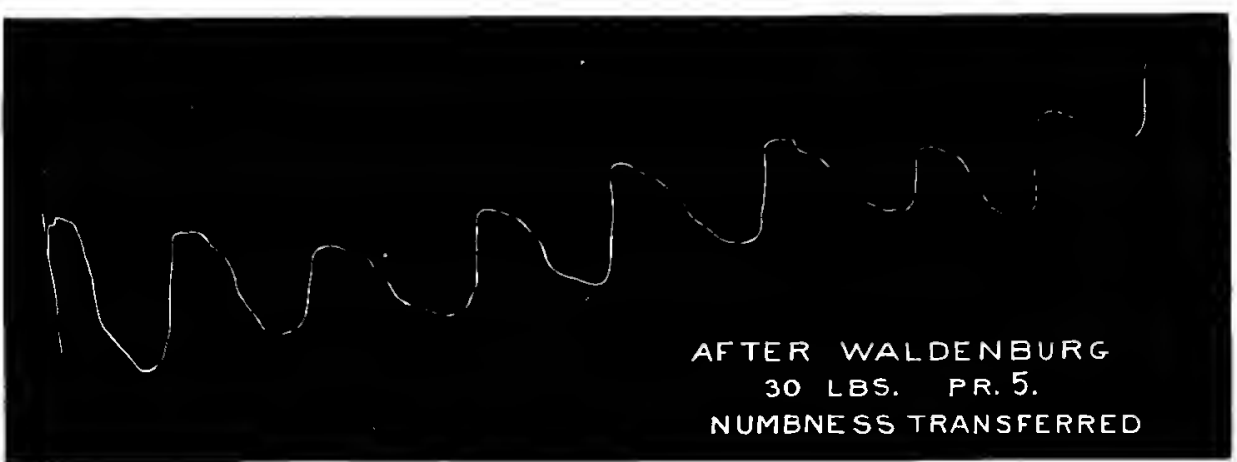

Condition of the Hiart.-Immediately after inhalation of one cylinder of air under pressure of 30 , lbs. or $\frac{1}{4 i}$ th of an 
atmosphere, trace No. II was taken. In this the percussion stroke is considerably increased in height, but the tidal wave is also increased, the collapse of the artery is prolonged, and there is an approach to a dicrotic notch. The respiratory base line rises to about the same extent in both tracings.

No. III was taken after three cylinders had been inhaled. The percussion stroke is lower than in the second trace, though higher than in the first, but the tidal wave is still more developed. This seems to indicate that, with an increased force of cardiac contraction, an increased resistance was now offered in the capillaries and arterioles. This might be owing to the greater amount of blood retained in them in a unity of time; or else, to an improved tone of the vaso motor centre, under increased respiratory stimulus and oxygenation.

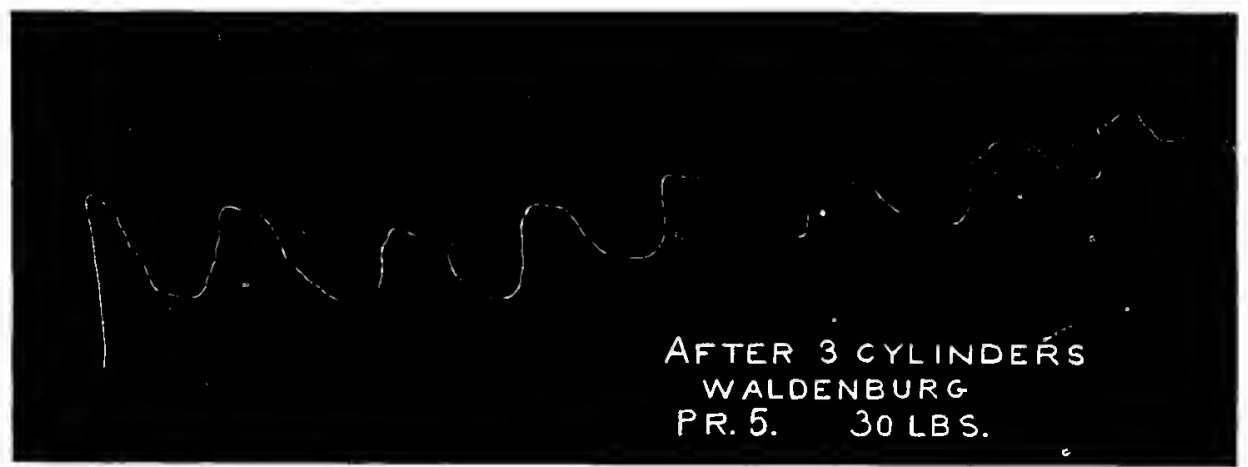

Coincidently with these modifications of the pulse, the patient noticed that the left side of the body was now free from numbness, while this was intensified on the right side, where, hitherto it had been scarcely perceptible. For several subsequent hours, the patient felt a great deal better, and continued to do so during four or five days of daily inhalation. She then ceased attendance, but in forty-eight hours symptoms returned : consisting now in clutching sensation at epigastrium, pains all through the limbs, ravenous hunger and profound mental depression; menstruation was then over-due five days. The patient was then ordered wine 
of cocoa, to each dose of which was added a grain of cocaine. This at once made her feel, (to use her own expression), "splendidly;" menstruation came on, and the nervous symptoms all disappeared.

The condition which persisted after the violent epileptic attack in this case was probably the hysteroid state, so well described by Gowers, and which that author interprets as indicating commencing nutritive degeneration of the brain.

The point of interest in this special attack, lies I think, in the phenomenon of transfer, which was effected by the compressed air inhalation as promptly as it is some times observed after the use of the metallic disks.

This transfer began immediately, and when the tracing showed no sign of an effect on the vaso motor system, but only of increased energy in the cardiac contraction.

If the numbness be attributed to temporary impairment of the nutrition of the cortical sensory centres, and of their circulation, two conditions may be implied. The chemical processes of synthesis and of deoxidation, resulting respectively in storage and in circulation of nerve force, must be slackened or nearly arrested, while the process of supplying nutritive material, and of eliminating of waste products must both be similarly reduced. The increased force of circulation determined by the compressed air inhalation, as well as the presumable, though slight increase in the oxygen carried by the blood, should both act in the same way upon the dyspncic nerve tissues. The greater supply of oxygen should stimulate the slackened chemical processes sustained in them; and by the greater rapidity of the blood stream, their lymphatic sheaths should be swept clear of accumulated waste products. In this way may be explained the relief afforded to the various paræsthesias complained of. But the transfer of the numbness from the left to the right side of the body remains unexplained. We may ask the following question: When in one portion of the cortex, depression of function is relieved, and an active circulation re-established, must there be a temporary recession of blood supply and nervous activity from other portions, until, after a succession of oscillations, complete equilibrium shall have been restored? 